\title{
Journal of Environmental Analytical Chemistry
}

\section{Determination of Pharmaceutical Pollutants in River Environment by the SPE- LC-MS/MS Method: A Mini Review}

Takashi Azuma* and Yoshiki Mino

Graduate School of Pharmaceutical Sciences, Osaka University of Pharmaceutical Sciences, 4-20-1 Nasahara, Takatsuki, Osaka 569-1094, Japan

*Corresponding author: Takashi Azuma, Graduate School of Pharmaceutical Sciences, Osaka University of Pharmaceutical Sciences, 4-20-1 Nasahara, Takatsuki, Japan, Tel: +81-72-690-1070; Fax: +81-72-690-1070; E-mail: t.azuma@gly.oups.ac.jp

Rec date: December 05, 2014, Acc date: December 29, 2014, Pub date: December 31, 2014

Copyright: () 2015 Azuma T et al., This is an open-access article distributed under the terms of the Creative Commons Attribution License, which permits unrestricted use, distribution, and reproduction in any medium, provided the original author and source are credited

\begin{abstract}
Recently, new pollution problems due to the presence of pharmaceuticals in the water environment have been reported, and research aimed at understanding the status of this pollution and assessing and dealing with the associated environmental risks is receiving worldwide attention. Because their concentrations in the water environment are quite low (roughly in the range from $\mathrm{ng} / \mathrm{L}$ to $\mu \mathrm{g} / \mathrm{L}$ ), a method of highly sensitive and highly selective multicomponent simultaneous analysis is indispensable for detecting and quantifying these products. Here, I summarize the findings of previous research and case study analyses to date of an analytical method that combines solid phase extraction (SPE) and liquid chromatography - tandem mass spectrometry (LC-MS/MS); this is a versatile and reliable method of detecting and quantifying pharmaceutical pollutants in river water and wastewater samples. I also discuss the prospects for environmental analysis techniques.
\end{abstract}

Keywords: Pharmaceuticals; River environment; Sewage treatment plant; Environmental analysis

\section{Introduction}

A newly emerging pollution problem in the water environmentthe detection of pharmaceuticals and personal care products (PPCPs) in the waters of rivers, lakes, and marshes and in drinking water sources-has recently begun to receive a large amount of attention. Because PPCPs are comprised of a diverse chemical compounds, in this review we focused on pharmaceuticals that were targeted as environmental water pollutants (pharmaceutical pollutants). Generally their concentrations are low (roughly in the range from ng/L to $\mu \mathrm{g} / \mathrm{L}$ ) worldwide [1-3]. Even in this low concentration range, however, there have been reports of the endocrine-disrupting chemicals these products contain having serious environmental impacts, such as feminization of males in fishes [4,5]. Pharmaceuticals are designed to have specific physiological effects on targeted areas of the body, so that even at low concentrations, concern is rising about their toxic effects on ecosystems and their impacts on human health via residues in drinking water $[1,6]$. Detection of pharmaceutical pollutants in the water environment is mainly derived from their biotic and abiotic recalcitrance after discharge into the environment $[1,2]$.

Pharmaceutical pollutants in the wastewater are transferred by sewerage systems to sewage treatment plants. However, because they are highly water soluble to make them easily discharged from the body and retained in the soluble state unattached on the sediments, they tend not to be removed during the traditional sewage treatment process, which is centered on biological treatment. Therefore, collected pharmaceutical pollutants are released into rivers without sufficient treatment $[7,8]$. Water discharged from sewage treatment plants is a major source of their pollutant loads in river basins $[9,10]$.

The history of pollution of water environments by recalcitrant pharmaceuticals are long and goes back to the 1970s [11,12]. At the time, for example, there was a report of the detection of the lipid- lowering agent clofibric acid [11] in the discharge water from a sewage treatment plant in the United States. The antipyretic analgesic agent salicylic acid, along with clofibric acid, was also detected in the discharge water from a sewage treatment plant in Germany [12]. Neither of these discoveries led to the establishment of research programs. Nevertheless, worldwide interest in this environmental pollution problem increased between the 1990s and 2000s, and an abundance of research targeting a wide range of their components covering more than 100 components of antibacterial, psychotropic, Xray contrast, antiseptic, antihypertensive, lipid-lowering, and antipyretic analgesic was launched worldwide. The scope of these research projects extended from research aimed at understanding the status of pharmaceuticals pollution [2,3] and their behavior in river environments $[13,14]$ to research aimed at understanding the behavior and removal of pharmaceutical pollutants at sewage treatment plants $[15,16]$, developing water treatment technologies to effectively remove $[17,18]$ or performing ecotoxicity impact assessments $[19,20]$. Figure 1 summarizes the concentration of each pharmaceutical pollutant detected in treated water discharged from sewage treatment plants into rivers $[9,21,22]$.

The increase in worldwide interest in the problem of pharmaceuticals-related water pollution is due partially to an increase in social interest in environmental problems. However, a large part is also due to the remarkable recent development and improvement of analytical equipment and technology $[23,24]$. In particular, the distribution of SPE-LC-MS/MS, which combines solid phase extraction (SPE) and liquid chromatography - tandem mass spectrometry (LC-MS/MS), and is capable of highly sensitive and highly selective simultaneous detection and quantification, helped to reveal the presence of pollutants in trace concentrations (in the range of $\mathrm{ng} / \mathrm{L}$ to $\mu \mathrm{g} / \mathrm{L}$ ) that had been difficult to detect by conventional analytical methods $[23,24]$. Here, we summarized the research reports that have used SPE, LC-MS, and LC-MS/MS to analyze pharmaceutical pollutants and discuss the future development of environmental analysis techniques. 


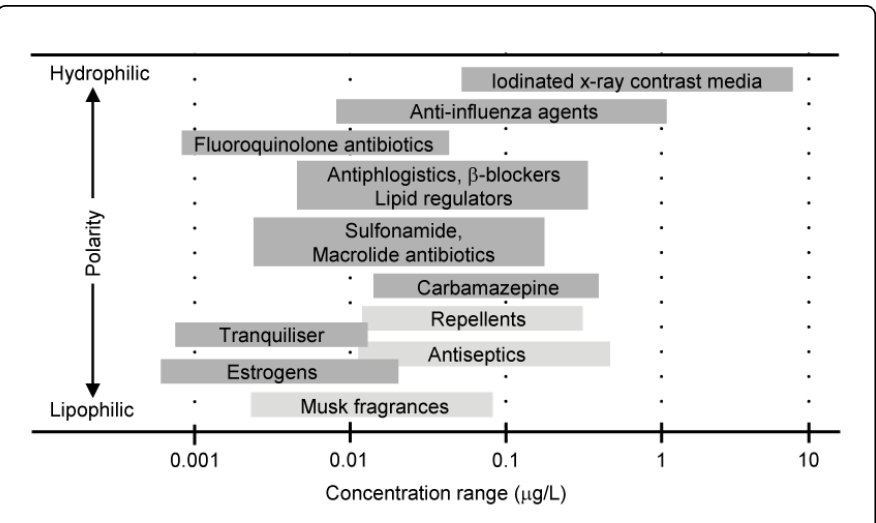

Figure 1: Ranges of measured concentration of pharmaceuticals (dark grey boxes) and personal care products (light grey boxes) in treated municipal wastewater $[9,21,22]$.

\section{Analytical Methods}

A highly sensitive and highly selective analytical method is indispensable for accurate analysis of the pharmaceutical pollutants coexisting in trace concentrations in river and sewage water along with many other substances [23-25]. Combining the sample preparation process of SPE, which concentrates and purifies water samples, with chromatography and MS enables the applied analytical method highly sensitive. Therefore, selection of the type of SPE cartridge, the amount of adsorbent, the elution solvent and its operation condition is a prerequisite key to the method invaluable. After pretreatment with the appropriate SPE, the recovered pharmaceutical pollutants are separated by liquid chromatography (LC) and identified and quantified by tandem mass spectrometry (MS/MS). For analysis of pharmaceutical pollutants which are highly polar, nonvolatile, and thermally unstable, adequateness of use of the combined methods of LC-MS/MS $[23,25,26]$ and LC/MS rather than gas chromatography (GC) and GC/MS is well known. Figure 2 summarizes the characteristics of the LC-MS(/MS) technique [27,28]. A resultant SPELC-MS/MS system has become an extremely versatile analytical method that is used not only analysis of pharmaceutical pollutants $[7,23,24]$ including endocrine disrupting chemical residues [29] in the water environment, but also in the food [30] and pharmaceuticals [31] fields. Below, we summarized the combined SPE-LC-MS/MS system for analysis of the pharmaceutical pollutants in the environment.

\section{Solid phase extraction}

To analyze pharmaceutical pollutants coexisting in river and sewage water samples along with many other substances in concentrations in the range from ng/L to $\mu \mathrm{g} / \mathrm{L}$, samples need to be concentrated to the level of $\mu \mathrm{g} / \mathrm{L}$, which is the concentration detection limit of LC-MS and LC-MS/MS [26, 32]. In addition, even though LC-MS(/MS) has high sensitivity and superior selectivity, impurities in the samples can interfere with the ionization of the target substances and thus drastically lower the sensitivity and accuracy of the analytical method $[29,33]$. Therefore, it is highly important to clean up impurities from the samples during preparation.

SPE is a sample preparation process based on the separation mechanism of LC. In SPE, a sample solution is passed through a column containing selective stationary adsorbent. The target substance is retained in the adsorbent, the impurities are washed and removed, and the target substance is eluted from the adsorbent with a solvent and collected [25,34]. SPE is a superior method that is not only simple and fast but also uses a very small amount of solvent for extraction, has superior purification and reproducibility, and can process many samples simultaneously and more efficiently than with liquid phase extraction, which is a liquid-liquid separation method that uses organic solvents to extract target components $[25,34]$.

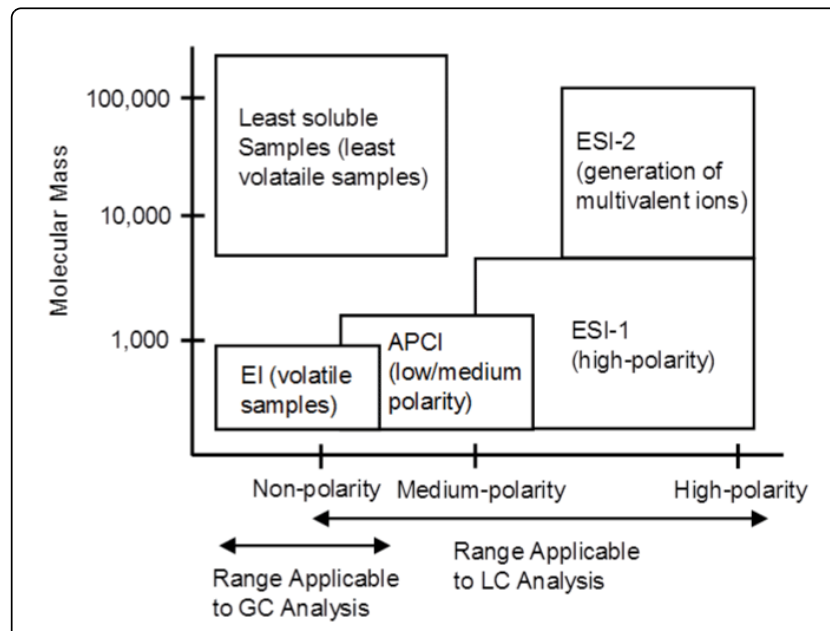

Figure 2: Ionization methods and applicable compounds [27,28]. (EI, electron ionization; APCI, atmospheric pressure chemical ionization; and ESI, electrospray ionization)

A wide variety of materials are used as the SPE stationary phase, beginning with the $\mathrm{C}_{18}$ stationary phase $[35,36]$ and a stationary phase with ion exchange groups[25,35]. We presented a typical use of the SPE for simultaneous determination of four representative antiinfluenza drugs, oseltamivir phosphate, oceltamivir carboxylate, zanamivir and amantadine by combination of strong-cationic SPE cartridge and liquid chromatography-tandem mass spectrometry (LCMS/MS) [9]. Special care must be taken for selection of the adsorbent to make the recovery rate higher because of the difference in adsorption-desorption profiles even if the same type ion-exchanger were used [41].

In research into general pharmaceutical pollutants in the water environment, Oasis HLB (Waters, Milford, MA, USA) is the stationary phase most frequently used in sample preparation [3,37,38]. Oasis HLB is a polymer sorbent; the stationary phase is a divinylbenzene-Nvinylpyrrolidone copolymer in which hydrophilic and lipophilic polymers are polymerized in a fine balance [38]. This property of the Oasis HLB makes it possible, in a single operation, to simultaneously analyze a wide variety of pharmaceutical pollutants that have not only combined lipophilic and hydrophilic properties but also a wide range of physicochemical qualities that are difficult to analyze simultaneously with $\mathrm{C}_{18}$ or other stationary phases based on only one type of interaction $[38,39]$. To perform an efficient SPE with a satisfactory rate of collection of the target substance it is indispensable to optimize the extraction conditions. Therefore, it is important to optimize the $\mathrm{pH}$ of the water sample loaded onto the stationary phase $[34,38,40]$ and the volume of the sample loaded onto the stationary phase $[35,40,41]$. It is also essential to clean up impurities $[25,38,41]$ and choose an eluent well suited to elution of the target component 
$[34,40,41]$. After the completion of SPE sample preparation, the processed sample is measured by either LC-MS or LC-MS/MS.

An application of online SPE-LC-MS was recently introduced in the field of food science and technology by Willenberg et al. [42]. In this system importance of the selection of the SPE column and the optimization of online-SPE procedure regarding extraction efficacy, reduction of ion suppressing matrix and carry over was also noted by Willenberg et al. [42] in addition to the case for analysis of human exposure to triclocarban [43].

\section{Liquid chromatography - mass spectrometry and liquid chromatography - tandem mass spectrometry}

In LC-MS, the target component is separated out during the LC part by using the difference in the target component's affinities for the stationary and mobile phases. The target component is then loaded onto the MS part along with the mobile phase and fragmented under atmospheric pressure, after which the fragment ions are measured by the detector for qualification and quantification of the target component $[23,26]$.

In contrast, in LC-MS/MS, in which the MS parts are connected in tandem mode, the first MS selects precursor ions, which are then further selected according to their mass-to-charge ratios $(\mathrm{m} / \mathrm{z})$. The further selected ions are fragmented by collision energy, and the fragment ions of the resulting product are measured by the second MS $[23,26]$. Thus the ions are selected twice by the MS/MS, allowing it to scan and analyze specific pairs of parent and daughter ions for each compound. This enables multiple reaction monitoring (MRM) with much higher analytical sensitivity and selectivity than with LC-MS [42, 43]. Electrospray ionization, which is a comparatively soft ionization technique, is used in the MS part of the detector [43,44]; a tandem quadrupole type or ion-trap type is usually used to separate the ions $[45,46]$. In addition, in recent years, to shorten measurement times and increase efficiency, ultra-performance liquid chromatography (UPLC) $[42,45,46]$ has become the major LC method used. It uses a column with a much smaller particle diameter $(1.7 \mu \mathrm{m})$ than that used in conventional LC ( 3 to $5 \mu \mathrm{m}$ ) and has superior pressure resistance.

In measurement using LC-MS/MS, optimization of the measurement conditions of the MS part is crucial. For this purpose, the first MS part performs an MS scan and determines the $\mathrm{m} / \mathrm{z}$ of the parent ions and the cone voltage at which the peak intensity of the parent ions is highest. Next, a daughter scan is performed to determine the $\mathrm{m} / \mathrm{z}$ of the daughter ions, and the collision energy is optimized so that it results in the highest peak intensity of the daughter ions. Finally, the combination at which the peak intensity for both parent ions and daughter ions is highest is determined for each component [44,47]. As a result of this procedure, a single MRM analysis can simultaneously analyze close to 100 components [48,49]. To optimize the LC part, the column that best suits the separation of the target component is chosen and the gradient conditions are optimized [42,43]. After optimization of the measurement conditions is completed, the samples are detected and quantified under these conditions.

Further instrumental development is now progress such as an online-SPE-LC-MS system [42,47]. Joining of the method presented above with such an innovative development would be useful in future for the evaluation of wide-spread PPCPs and pharmaceuticals including pollutants, suggesting the potential use for environmental evaluation needs and possible risk management.

\section{Conclusions}

Here, I have presented a literature review of the use of the highly sensitive and highly selective analytical method SPE-LC/MS/MS to detect pharmaceuticals, which are causing new problems with environmental pollution. SPE-LC/MS/MS is the main method used to assess the status of this pollution. I have also organized and clarified the knowledge accumulated in published analytical cases and discussed the future prospects of this environmental analysis technique.

Research into pharmaceutical pollutants in the water environment by using SPE-LC-MS/MS is progressing day by day. Recently, analyses using this method have begun to reveal that among these pharmaceutical pollutantss are antibacterial agents that could intensify the development of drug-resistant bacteria in the water environment [8]. Anti-influenza drugs in the water environment could foster the development of drug-resistant viruses carried by wild waterfowl and their spread to humans [22]. There is also the issue of the detection of narcotics and stimulants [48-50] in the water environment.

Research that aims to automate and mechanize the series of operations needed to perform SPE and LC-MS/MS is also being attempted $[45,51,52]$. Further future development of SPE-LC-MS/MS analytical techniques joining with online SPE-LC-MS and such a kind of innovative technology is expected to promote more detailed assessment of the environmental risks posed by wide range pollutants derived from PPCPs and pharmaceuticals.

\section{Acknowledgments}

We acknowledge River Foundation and Lake Biwa-Yodo River Water Quality Preservation Organization for funding in the form of research and scholarships.

\section{References}

1. Daughton CG, Ternes TA (1999) Pharmaceuticals and personal care products in the environment: Agents of subtle change?. Environ Health Perspect 107: 907-938.

2. Ternes TA (1998) Occurrence of drugs in German sewage treatment plants and rivers. Water Res 32: 3245-3260.

3. Kolpin DW, Furlong ET, Meyer MT, Thurman EM, Zaugg SD, et al. (2002) Pharmaceuticals, hormones, and other organic wastewater contaminants in U.S. streams, 1999-2000: A national reconnaissance. Environ Sci Technol 36: 1202-1211.

4. Jobling S, Williams R, Johnson A, Taylor A, Gross-Sorokin M, et al. (2005) Predicted exposures to steroid estrogens in U.K. rivers correlate with widespread sexual disruption in wild fish populations. Environ Health Perspect 114: 32-39.

5. Bound JP, Voulvoulis N (2004) Pharmaceuticals in the aquatic environment-a comparison of risk assessment strategies. Chemosphere 56: 1143-1155.

6. Celiz MD, Tso J, Aga DS (2009) Pharmaceutical metabolites in the environment: analytical challenges and ecological risks. Environ Toxicol Chem 28: 2473-2484.

7. Narumiya M, Nakada N, Yamashita N, Tanaka H (2013) Phase distribution and removal of pharmaceuticals and personal care products during anaerobic sludge digestion. J Hazard Mater 260: 305-312.

8. Michael I, Rizzo L, McArdell CS, Manaia CM, Merlin C, et al. (2013) Urban wastewater treatment plants as hotspots for the release of antibiotics in the environment: A review. Water Res 47: 957-995. 
9. Azuma T, Nakada N, Yamashita N, Tanaka H (2013) Mass balance of anti-influenza drugs discharged into the Yodo River system, Japan, under an influenza outbreak. Chemosphere 93: 1672-1677.

10. Kumar V, Hanamoto S, Johnson AC, Yamashita N, Nakada N, et al. (2014) Elevated risk from estrogens in the Yodo River basin (Japan) in winter and ozonation as a management option. Environ Sci: Processes \& Impacts 16: 232-238.

11. Garrison AW, Pope JD, Allen FR (1976) GC/MS analysis of organic compounds in domestic wastewaters. In: Keith LH (eds) Identification and Analysis of Organic Pollutants in Water, Ann Arbor Science Publishers, Ann Arbor, MI, USA; The first GC-MS determination of clofibric acid aeol-rc, in WWTP effluents.

12. Hignite C, Azarnoff DL (1977) Drugs and drug metabolites as environmental contaminants: Chlorophenoxyisobutyrate and salicylic acid in sewage water effluent. Life Sci 20: 337-341.

13. Yamamoto H, Nakamura Y, Moriguchi S, Nakamura Y, Honda Y, et al. (2009) Persistence and partitioning of eight selected pharmaceuticals in the aquatic environment: Laboratory photolysis, biodegradation, and sorption experiments. Water Res 43: 351-362.

14. Andreozzi R, Raffaele M, Nicklas P (2003) Pharmaceuticals in STP effluents and their solar photodegradation in aquatic environment. Chemosphere 50: 1319-1330.

15. Miège C, Choubert JM, Ribeiro L, Eusèbe M, Coquery M (2009) Fate of pharmaceuticals and personal care products in wastewater treatment plants - Conception of a database and first results. Environ Pollut 157: 1721-1726.

16. McArdell CS, Molnar E, Suter MJF, Giger W (2003) Occurrence and fate of macrolide antibiotics in wastewater treatment plants and in the Glatt Valley watershed, Switzerland. Environ Sci Technol 37: 5479-5486.

17. Ternes TA, Stüber J, Herrmann N, McDowell D, Ried A, et al. (2003) Ozonation: a tool for removal of pharmaceuticals, contrast media and musk fragrances from wastewater? Water Res 37: 1976-1982.

18. Wang L, Albasi C, Faucet-Marquis V, Pfohl-Leszkowicz A, Dorandeu C, et al. (2009) Cyclophosphamide removal from water by nanofiltration and reverse osmosis membrane. Water Res 43: 4115-4122.

19. Perrodin Y, Boillot C, Angerville R, Donguy G, Emmanuel E (2011) Ecological risk assessment of urban and industrial systems: A review. Sci Total Environ 409: 5162-5176.

20. Yamamoto H, Tamura I, Hirata Y, Kato J, Kagota K, et al. (2011) Aquatic toxicity and ecological risk assessment of seven parabens: Individual and additive approach. Sci Total Environ 410-411: 102-111.

21. Ternes TA, Joss A (2006) Human pharmaceuticals, hormones and fragrances. In: Ternes TA, Joss A (eds) The challenge of micropollutants in urban water management, IWA Publishing, New york, London.

22. Azuma T, Nakada N, Yamashita N, Tanaka H (2012) Synchronous dynamics of observed and predicted values of anti-influenza drugs in environmental waters during a seasonal influenza outbreak. Environ Sci Technol 46: 12873-12881.

23. Barceló D, Petrovic M (2007) Challenges and achievements of LC-MS in environmental analysis: 25 years on. TrAC Trends in Anal Chem 26: 2-11.

24. Shao B, Chen D, Zhang J, Wu Y, Sun C (2009) Determination of 76 pharmaceutical drugs by liquid chromatography-tandem mass spectrometry in slaughterhouse wastewater. J Chromatogr A 1216: 8312-8318.

25. Al-Odaini NA, Zakaria MP, Yaziz MI, Surif S (2010) Multi-residue analytical method for human pharmaceuticals and synthetic hormones in river water and sewage effluents by solid-phase extraction and liquid chromatography-tandem mass spectrometry. J Chromatogr A 1217: 6791-6806.

26. Hao C, Zhao X, Yang P (2007) GC-MS and HPLC-MS analysis of bioactive pharmaceuticals and personal-care products in environmental matrices. TrAC Trends in Anal Chem 26: 569-580.

27. Shimadzu Corporation (2014) Introduction to LC-MS, Atmospheric pressure ionization method.
28. Zhou B, Xiao JF, Tuli L, Ressom HW (2012) LC-MS-based metabolomics. Mol BioSyst 8: 470-481.

29. Kumar V, Nakada N, Yasojima M, Yamashita N, Johnson AC, et al. (2009) Rapid determination of free and conjugated estrogen in different water matrices by liquid chromatography-tandem mass spectrometry. Chemosphere 77: 1440-1446.

30. Moret S, Barp L, Grob K, Conte LS (2011) Optimised off-line SPE-GCFID method for the determination of mineral oil saturated hydrocarbons (MOSH) in vegetable oils. Food Chem 129: 1898-1903.

31. Lindegårdh N, Hien TT, Farrar J, Singhasivanon P, White NJ, Day NPJ (2006) A simple and rapid liquid chromatographic assay for evaluation of potentially counterfeit Tamiflu. J Pharm Biomed Anal 42: 430-433.

32. Zhang ZL, Zhou JL (2007) Simultaneous determination of various pharmaceutical compounds in water by solid-phase extraction-liquid chromatography-tandem mass spectrometry. J Chromatogr A 1154: 205-213.

33. Vieno NM, Tuhkanen T, Kronberg L (2006) Analysis of neutral and basic pharmaceuticals in sewage treatment plants and in recipient rivers using solid phase extraction and liquid chromatography-tandem mass spectrometry detection. J Chromatogr A 1134: 101-111.

34. Weigel S, Kallenborn R, Hühnerfuss H (2004) Simultaneous solid-phase extraction of acidic, neutral and basic pharmaceuticals from aqueous samples at ambient (neutral) $\mathrm{pH}$ and their determination by gas chromatography-mass spectrometry. J Chromatogr A 1023: 183-195.

35. Castiglioni S, Bagnati R, Calamari D, Fanelli R, Zuccato E (2005) A multiresidue analytical method using solid-phase extraction and highpressure liquid chromatography tandem mass spectrometry to measure pharmaceuticals of different therapeutic classes in urban wastewaters. J Chromatogr A 1092: 206-215.

36. Pawlowski S, Ternes TA, Bonerz M, Rastall AC, Erdinger L, et al. (2004) Estrogenicity of solid phase-extracted water samples from two municipal sewage treatment plant effluents and river Rhine water using the yeast estrogen screen. Toxicol Vitro 18: 129-138.

37. Okuda T, Yamashita N, Tanaka H, Matsukawa H, Tanabe K (2009) Development of extraction method of pharmaceuticals and their occurrences found in Japanese wastewater treatment plants. Environ Int 35: 815-820.

38. Gómez MJ, Petrović M, Fernández-Alba AR, Barceló D (2006) Determination of pharmaceuticals of various therapeutic classes by solidphase extraction and liquid chromatography-tandem mass spectrometry analysis in hospital effluent wastewaters. J Chromatogr A 1114: 224-233.

39. Ding Y, Teppen BJ, Boyd SA, Li H (2013) Measurement of associations of pharmaceuticals with dissolved humic substances using solid phase extraction. Chemosphere 91: 314-319.

40. Dahane S, Gil García MD, Martínez Bueno MJ, Uclés Moreno A, Martínez Galera M, et al. (2013) Determination of drugs in river and wastewaters using solid-phase extraction by packed multi-walled carbon nanotubes and liquid chromatography-quadrupole-linear ion trap-mass spectrometry. J Chromatogr A 1297: 17-28.

41. Azuma T, Nakada N, Yamashita N, Tanaka H (2014) Optimisation of the analysis of anti-influenza drugs in wastewater and surface water. Int J Environ Anal Chem 94: 853-862.

42. Michael I, Hapeshi E, Michael C, Fatta-Kassinos D (2012) Development and validation of a UPLC-MS/MS method for studying the degradation kinetics of ofloxacin and trimethoprim during the application of solar Fenton process in secondary treated sewage. Water Sci Technol 66: 1574-1581.

43. Schultz MM, Furlong ET (2008) Trace analysis of antidepressant pharmaceuticals and their select degradates in aquatic matrixes by LC/ESI/MS/MS. Anal Chem 80: 1756-1762.

44. Gros M, Petrović M, Barceló D (2006) Development of a multi-residue analytical methodology based on liquid chromatography-tandem mass spectrometry (LC-MS/MS) for screening and trace level determination of pharmaceuticals in surface and wastewaters. Talanta 70: 678-690.

45. Bourdat-Deschamps M, Leang S, Bernet N, Daudin J-J, Nélieu S (2014) Multi-residue analysis of pharmaceuticals in aqueous environmental 
Citation: Azuma and Mino (2015) Determination of Pharmaceutical Pollutants in River Environment by the SPE-LC-MS/MS Method: A Mini Review. J Environ Anal Chem 2: 125. doi:10.4172/JREAC.1000125

Page 5 of 5

samples by online solid-phase extraction-ultra-high-performance liquid chromatography-tandem mass spectrometry: Optimisation and matrix effects reduction by quick, easy, cheap, effective, rugged and safe extraction. J Chromatogr A 1349: 11-23.

46. Kasprzyk-Hordern B, Dinsdale RM, Guwy AJ (2007) Multi-residue method for the determination of basic/neutral pharmaceuticals and illicit drugs in surface water by solid-phase extraction and ultra-performance liquid chromatography-positive electrospray ionisation tandem mass spectrometry. J Chromatogr A 1161: 132-145.

47. López-Serna R, Petrović M, Barceló D (2011) Development of a fast instrumental method for the analysis of pharmaceuticals in environmental and wastewaters based on ultra-high performance liquid chromatography (UHPLC)-tandem mass spectrometry (MS/MS). Chemosphere 85: 1390-1399.

48. López-Serna R, Petrović M, Barceló D (2012) Occurrence and distribution of multi-class pharmaceuticals and their active metabolites and transformation products in the Ebro River basin (NE Spain). Sci Total Environ 440: 280-289.

49. Ferrer I, Zweigenbaum JA, Thurman EM (2010) Analysis of 70 Environmental Protection Agency priority pharmaceuticals in water by EPA Method 1694. J Chromatogr A 1217: 5674-5686.

50. Pal R, Megharaj M, Kirkbride KP, Naidu R (2013) Illicit drugs and the environment -A review. Sci Total Environ 463-464: 1079-1092.

51. López-Serna R, Pérez S, Ginebreda A, Petrović M, Barceló D (2010) Fully automated determination of 74 pharmaceuticals in environmental and waste waters by online solid phase extraction-liquid chromatographyelectrospray-tandem mass spectrometry. Talanta 83: 410-424.

52. Kataoka H, Shiba H, Saito K (2012) Automated analysis of oseltamivir and oseltamivir carboxylate in environmental waters by online in-tube solid-phase microextraction coupled with liquid chromatographytandem mass spectrometry. Anal Meth: 1513-1518. 